\title{
Stellate figure in the macula: visualization in the Henle fiber layer on optical coherence tomography
}

This article was published in the following Dove Press journal:

Clinical Optometry

15 January 2014

Number of times this article has been viewed

\section{Shinji Makino \\ Meri Watanabe \\ Hironobu Tampo \\ Department of Ophthalmology, Jichi Medical University, Shimotsuke, Tochigi, Japan}

\begin{abstract}
A 21-year-old woman complaining of a sudden visual disturbance in her left eye was referred to our hospital. The best-corrected visual acuity (BCVA) in the left eye was 0.3 . Fundus examination revealed tortuous retinal veins, soft exudates, and retinal edema. Optical coherence tomography showed that the macular thickness was increased to $685 \mu \mathrm{m}$. We diagnosed the condition as a central retinal vein occlusion. Systemic administration of an antiplatelet agent was initiated. The BCVA improved to 0.6 , the retinal edema dramatically resolved, and the macular thickness was reduced to $318 \mu \mathrm{m} 1$ week later. Furthermore, the reduced retinal edema had transformed to many spokes in a wheel of exudates, a so-called "stellate figure", in the macula. On optical coherence tomography, hyper-reflective substances were detected in the Henle fiber layer. One month later, the BCVA improved to 1.0. Changes in microstructural findings and visual acuity were analogous during the recovery of macular edema in our patient.
\end{abstract}

Keywords: stellate figure in the macula, Henle fiber layer, central retinal vein occlusion, macular edema, optical coherence tomography

\section{Introduction}

A stellate figure in the macular region is found in many conditions. ${ }^{1}$ The combined signs of macular star, vessel caliber changes, and hemorrhages may indicate hypertension, diabetes, papilledema, optic neuritis, or chronic nephritis, depending on the patient. The spokes in the wheel of the exudate extending from the macular hub may be sparse or numerous, thin lines, or broad elevated exudates. All exudate lines become fine dots before complete absorption. ${ }^{1}$

Although central retinal vein occlusion (CRVO) is most commonly seen in older patients, it occasionally occurs in patients younger than 50 years of age..$^{2,3}$

To our knowledge, several reports in the literature have described a stellate figure with CRVO, ${ }^{1-3}$ but reports describing CRVO with a stellate figure in the macula, as examined by optical coherence tomography (OCT), are extremely rare. Herein, we report the latter finding in a 21-year-old woman.

\section{Case report}

A 21-year-old Japanese woman complaining of the development of a sudden, painless, visual disturbance in the left eye upon waking 3 days earlier was referred to our hospital. Her personal and family histories were unremarkable. On ophthalmic examination, the best-corrected visual acuity (BCVA) in the left eye was 0.3 and the acuity in the left eye was 1.2. The ocular pressures were normal. Slit-lamp examination did not reveal abnormalities in either anterior segment. Fundus examination revealed tortuous retinal veins,
Correspondence: Shinji Makino

Department of Ophthalmology, Jich Medical University, 33 I I-I Yakushiji,

Shimotsuke, Tochigi 329-0498, Japan

Tel +8I 285587382

Fax +8I 285448365

Email makichan@jichi.ac.jp submit your manuscript | www.dovepress.com

Dovepress

http://dx.doi.org/10.2147/OPTO.\$58779
Clinical Optometry 20 I4:6 I-3

(c) (i) (5) 2014 Makino et al. This work is published by Dove Medical Press Limited, and licensed under Creative Commons Attribution - Non Commercial (unported, v3.0) LY LC License. The full terms of the License are available at http://creativecommons.org/licenses/lby-nc/3.0/. Non-commercial uses of the work are permitted without any further pew to how to request permission may be found at: http://www.dovepress.com/permissions.php 
soft exudates, and retinal edema in the left eye (Figure 1A, arrows). In contrast, no abnormal findings were observed in the right eye. Fluorescein angiography demonstrated marked hyperfluorescence of the retinal veins and optic disc in the left eye (Figure 2A and B). OCT (RS-3000; Nidek Co, Ltd, Gamagori, Japan) revealed increased macular thickness $(685 \mu \mathrm{m})$ and hyper-reflectivity in the outer plexiform layer (Figure 3A, arrows). Her blood laboratory findings, electrocardiogram, and chest X-ray examinations were unremarkable. We diagnosed the condition as a CRVO probably due to papillophlebitis. Firstly, systemic administration of an antiplatelet agent was initiated. The BCVA improved to 0.6 , the retinal edema dramatically resolved, and the macular thickness was reduced to $318 \mu \mathrm{m} 1$ week later (Figure 3B). Furthermore, the reduced retinal edema was transformed to many spokes in a wheel of exudates, a so-called "stellate figure", in the macula (Figure 1B), and hyper-reflective substances were detected in the Henle fiber layer (HFL) (Figure 3B, arrows). The BCVA recovered to 1.0, the stellate figure showed gradual improvement 1 month later (Figure 1C), and the hyper-reflective substances detected in the HFL had transformed to fine dots (Figure 3C, arrows).

\section{Discussion}

Although most commonly seen in older patients, CRVO occasionally occurs in patients younger than 50 years of age. ${ }^{2,3}$ In older patients, CRVO is often associated with systemic vascular disease and other systemic conditions, such as hypertension, diabetes, hyperlipidemia, and platelet abnormalities. ${ }^{2,3}$ Although CRVO in young adults is occasionally associated with a systemic disease, the cause is unknown in the vast majority of cases. It has been suggested that inflammation of the central retinal vein may cause the occlusion. The appearance of unilateral optic disc edema, dilatation, and tortuosity of the major retinal veins with a variable amount of retinal hemorrhage in young, healthy adults who report blurred vision or photopsia has been called papillophlebitis, benign retinal vasculitis, optic disc vasculitis, ${ }^{4}$ and nonischemic CRVO. The largest case series analysis of

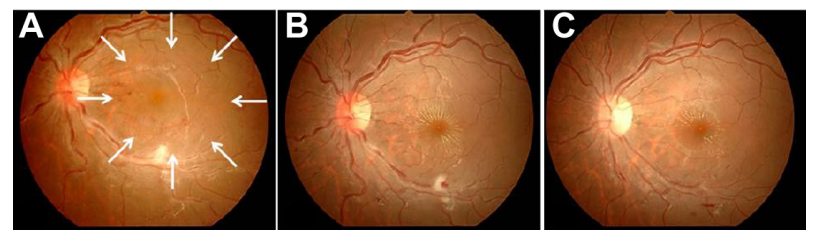

Figure I Left fundus photographs.

Notes: (A) Initial visit; (B) I week after the initial visit; (C) I month after the initial visit. Images show (A) retinal edema (arrows), (B) transformation to a "stellate figure", and (C) reduced hard exudates.
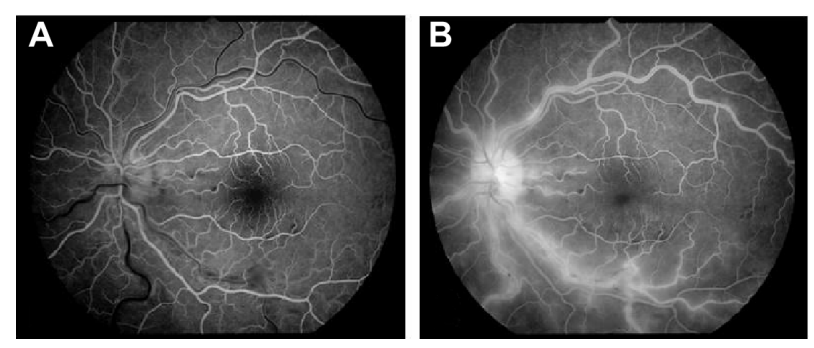

Figure 2 Left fluorescein angiography demonstrated marked hyperfluorescence of the retinal veins and optic disc.

Notes: (A) Early phase; (B) late phase.

CRVO in young adults was conducted by Fong and Schatz, ${ }^{3}$ who evaluated 103 patients. According to their report, an exudate was found in the macula in $15 \%$ of the cases. The exudate was often observed to have a macular star appearance, either as a complete or partial star. Whether the star is partial or complete, the side toward the disc is usually the most prominent, and the disc-side fan has no differentiating value. In addition, the presence of an exudate in young
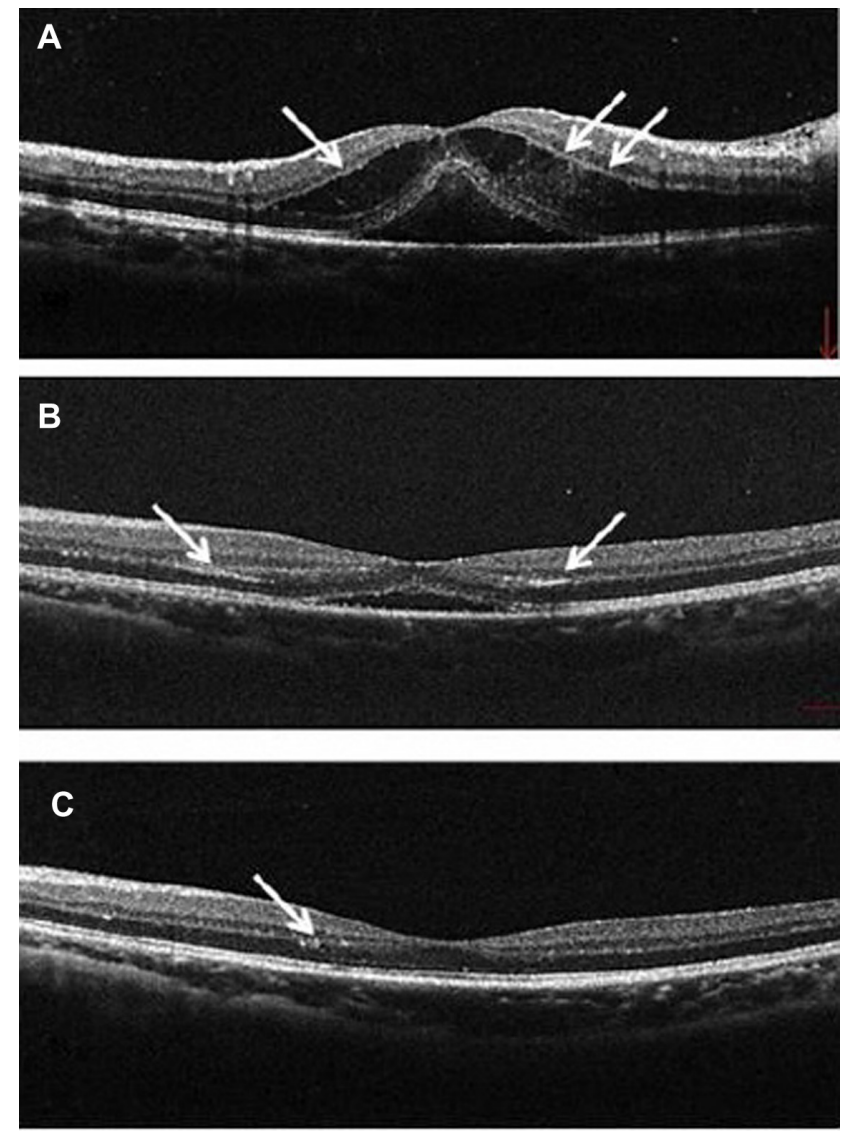

Figure 3 Optical coherence tomography images of the left fundus.

Notes: (A) Initial visit; (B) I week later; (C) I month later. The images show (A) marked retinal edema and hyper-reflectivity in the outer plexiform layer (arrows), (B) reduced retinal edema and hyper-reflective substances in the Henle fiber layer (arrows), and (C) hyper-reflective substances transformed to fine dots (arrows). 
adults with CRVO appears to indicate a better prognosis for visual outcomes. The reason for the better prognosis may be that the macular exudate indicates both some reabsorption of fluid and some degree of CRVO resolution. Further, the exudate may be obscured by hemorrhages in more severe cases of CRVO. In our patient, the BCVA recovered to 1.0 and the stellate figure showed gradual improvement 1 month after the initial visit.

The retinal nerve fiber layer, the junction between the inner and outer segments of the photoreceptors, and the retinal pigment epithelium have a high degree of backscattering, which produces highly-reflective bands on the OCT images. The inner and outer plexiform layers (OPL) have more backscattering, as compared to the ganglion cell layer and the inner and outer nuclear layers. The OPL is truly plexiform only in its inner third region (photoreceptor synapses); in contrast, the outer two-thirds of the OPL comprise axonal extensions (Henle fibers) of the photoreceptors, which are enveloped by the lucent outer cytoplasm of Müller cells. Henle fibers run obliquely from the center out to their pedicles; these fibers are typically not visualized on standard OCT images because most backscattering from the HFL is beyond the range of the measurement axis. ${ }^{5}$ In 2011, Otani et $\mathrm{al}^{5}$ sought to improve HFL imaging with OCT by using an incident angle of the measurement beam perpendicular to the HFL. In their study, OCT revealed a highly-reflective OPL in the half of the macula that was tilted down, where a measurement beam perpendicular to the HFL generated strong backscattering. Ahlers et al, ${ }^{6}$ who used OCT in patients with acute central serous chorioretinopathy (CSC), reported that hyper-reflectivity could be imaged in the outer nuclear layer and in the OPL in the area where a detached neurosensory retina is evident, and suggested that hyper-reflectivity represents intraretinal changes that indicate the presence of subretinal pathologies or retinal maladjustment caused by underlying pathologies. In CSC, macular elevation resulting from subretinal fluid causes the detached retina to tilt toward the fovea, which results in strong backscattering, because the direction of the measurement beam is almost perpendicular to the Henle fibers in the area of the detached neurosensory retina. Therefore, intraretinal hyper-reflectivity in CSC is likely to represent backscattering from the HFL. For this reason, backscattering is likely to decrease because of fluid accumulation in the HFL, as well as because of changes in the running direction of the Henle fibers. Interestingly, in our case, the hyper-reflectivity of the OPL associated with marked macular edema in the acute phase and the hyper-reflective substances corresponding to a hard exudate in the HFL following improvement of macular edema were detected on OCT. Changes in microstructural findings and visual acuity were analogous during recovery of macular edema in our patient. Finally, OCT was useful for demonstrating macular edema visualization, as well as localization of hard exudates in the HFL in a patient with a stellate figure in the macula.

\section{Disclosure}

The authors report no conflicts of interest in this work.

\section{References}

1. Bedell AJ. The stellate figure in the macular region. Trans Am Ophthalmol Soc. 1953;51:257-272.

2. Fong AC, Schatz H, McDonald HR, et al. Central retinal vein occlusion in young adults (papillophlebitis). Retina. 1991;12(1):3-11.

3. Fong AC, Schatz H. Central retinal vein occlusion in young adults. Surv Ophthalmol. 1993;37(6):393-417.

4. Hayreh SS. Optic disc vasculitis. Br J Ophthalmol. 1972;56(9): 652-670.

5. Otani T, Yamaguchi Y, Kishi S. Improved visualization of Henle fiber layer by changing the measurement beam angle on optical coherence tomography. Retina. 2011;31(3):497-501.

6. Ahlers C, Geitzenauer W, Stock G, Golbaz I, Schmidt-Erfurth U, Prünte C. Alterations of intraretinal layers in acute central serous chorioretinopathy. Acta Ophthalmol. 2009;87(5):511-516.
Clinical Optometry

\section{Publish your work in this journal}

Clinical Optometry is an international, peer-reviewed, open access journal publishing original research, basic science, clinical and epidemiological studies, reviews and evaluations on clinical optometry. All aspects of patient care are addressed within the journal as well as the practice of optometry including economic and business analyses. Basic and clinical

\section{Dovepress}

research papers are published that cover all aspects of optics, refraction and its application to the theory and practice of optometry. The manuscript management system is completely online and includes a very quick and fair peer-review system, which is all easy to use. Visit http://www.dovepress. com/testimonials.php to read real quotes from published authors. 